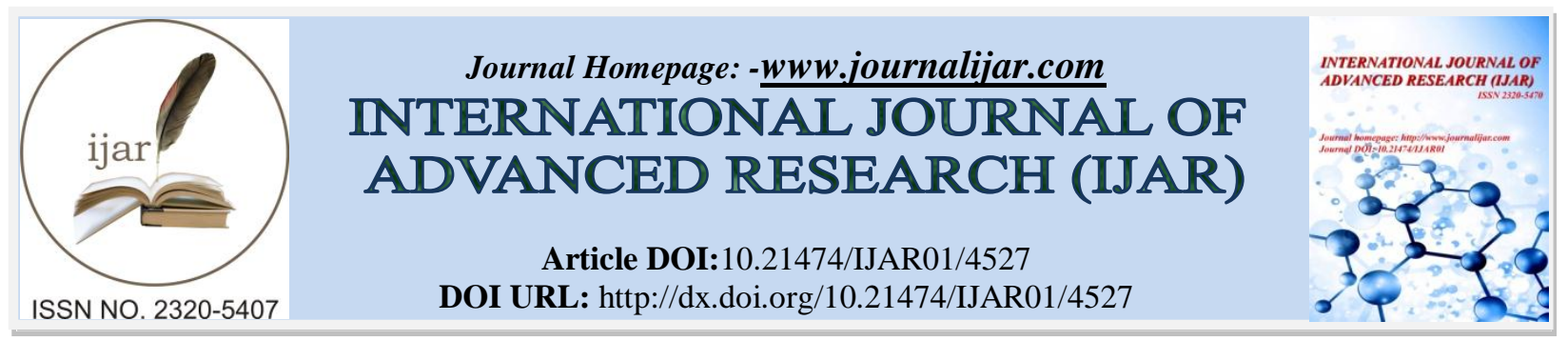

RESEARCH ARTICLE

\title{
WASTE WATER QUALITY OF EDIBLE OIL REFINERY OF RAJNANDGAON (C.G.) BEFORE TREATMENT AND AFTER TREATMENT.
}

Dr. Rubina Alvi and Dr. H. Mohabey. Govt. Digvijay College, Rajnandgaon (C.G.)

\section{Manuscript Info}

Manuscript History

Received: 19 April 2017

Final Accepted: 21 May 2017

Published: June 2017

Key words:-

Edible oil, Industry, Operational parameter effluent treatment, $\mathrm{pH}$, organic material.

\section{Abstract}

Present paper describes the quality of waste water coming out from vegetable oil refinery plant before passing to effluent treatment plant. The study shows that the waste water coming out from vegetable oil refinery plant has heavy pollution load of organic matter, sulphate phosphate and chloride. This waste water when treated in effluent treatment plant the organic pollution load decreases but use of calcium chloride and Alum as coagulants increases the concentration of chlorides in the final treatment of waste water, A comparison of water quality parameters suggest further treatment of waste water coming out from treatment plant to make it useful for agriculture and domestic use.

Copy Right, IJAR, 2017,. All rights reserved.

\section{Introduction:-}

The refined edible oil manufacturing units generate solid waste (spent earth) and waste water, the waste water come out from oil refinery create serious environmental problem, great threat to aquatic life due to its high organic content. Hence its treatment is essential prior to its disposal. The choice of effluent treatment method depends on the organic contents present in the effluent and its discharge condition.

In edible oil industry, waste water mainly generated from the degumming, deacidification \& deodorization and neutralization step, sodium salt of free Fatty acid (soap stocks) are produced whose splitting through the use of $\mathrm{H}_{2} \mathrm{SO}_{4}$ generates highly acidic and oily waste water. Its characteristics depend largely on the type of oil processed and on the process implemented that are high in COD, oil grease, sulphate phosphate content, resulting in both high inorganic as well as organic loading of the relevant waste water treatment works (Aslan at el, 2009) ${ }^{1}$

Edible oil effluent can be treated either separately or in conjugation by chemical or biological means. The problems with chemical treatment are the increased chemical handling costs and the production of chemical sludge that is difficult to treat and dispose. Biological treatment methods offer an easy and cost effective alternative to chemical methods in the treatment of edible oil effluent.

Biological treatment of edible oil waste water could be treated by conventional Activated sludge process and sequencing Batch Reactor [Bux et al 2000] ${ }^{2}$ In conventional activated sludge process the edible oil refinery effluent treatment plant (ETP) comprises of following units viz, equalization basin, neutralization unit, clarifloccular Primary clarifier and filter press. The waste water is first pumped into an equalization basin, where the floating oil is skimmed out. The waste water is neutralized with addition of lime \& is pumped to a clariflocculator where alum is added. 
The addition of alum results in fast settling of lime sludge, which is drained out and passed through the filter press. The overflow of supernatant phosphate as nutrient and let into aeration basin for biological treatment. The surface aerator are provided in aeration basin for oxygen transfer and mixing of biomass with waste water. The overflow from aeration basin passes through a clarifier. The residual colour of the treated effluent is removed by the addition of sodium hypochlorite solution. (E-tang2011) ${ }^{3}$

Activated sludge process is potentially viable to treat edible oil refinery waste water only for removal of COD,BOD, TSS, Fecal coliform and upgrade of $\mathrm{pH}$ and DO recovery and TKN and phosphate up to particular limit (Sandile $\mathrm{P}$ Makhijze et al 2001) ${ }^{4}$

Use of these methods disposal and waste treatment still remain major challenges in fast growing oil industry (chipasa KB limits, polish Journal 2001; 10(3) p.p-141-147) ${ }^{5}$

\section{Experiment and Result:-}

Waste water samples were collected from edible oil refinery of Rajnandgaon (C.G.) before treatment and then the effluent coming out from ETP. These samples were analysed for different water quality parameters. The results are summarised in Table- 1

Table-1:- Waste water Analysis before and after treatment.

\begin{tabular}{|c|c|c|c|}
\hline \multicolumn{2}{|r|}{ Before ETP Treatment. } & \multicolumn{2}{|c|}{ After ETP Treatment } \\
\hline 1 & Total suspended solid & $20320 \mathrm{ppm}$ & $487 \mathrm{ppm}$ \\
\hline 2 & Total hardness & $31 \mathrm{ppm}$ & 1224 ppm (increase) \\
\hline 3 & Electrical conductivity & 1.07 & 40.3 increased mho $\mathrm{cm}^{-1}$ \\
\hline 4 & Phosphate & $1.49 \mathrm{ppm}$ & $13.2 \mathrm{ppm}$ \\
\hline 5 & Nitrate & $4.6 \mathrm{ppm}$ & $2.9 \mathrm{ppm}$ \\
\hline 6 & Total alkalinity as $\mathrm{c}_{\mathrm{a}} \mathrm{co}_{3}$ & 440 & Nil \\
\hline 7 & Nitrogen & 0.001 & .006 \\
\hline 8 & Chloride & 57 & 390 ppm increase \\
\hline 9 & Sulphate & 162 & $9224 \mathrm{ppm}$ increase \\
\hline 10 & COD & 25000 & 2160 (high) \\
\hline 11 & BOD & 9800 & 800 high \\
\hline 12 & $\mathrm{Fe}$ & less than 0.1 & Nil \\
\hline 13 & $\mathrm{Zn}$ & 0.29 & $4.95 \mathrm{ppm}$ high \\
\hline 14 & Mo & 0.038 & $2.24 \mathrm{ppm}$ high \\
\hline 15 & $\mathrm{Hg}$ & $<0.001$ & $<0.0001$ \\
\hline 16 & $\mathrm{Cd}$ & 0.12 & $0.10 \mathrm{ppm}$ \\
\hline
\end{tabular}

\section{Variation in pH:-}

The water is highly acidic before treatment but after treatment it is maintained the $\mathrm{pH}$ of treated water has $8.0 \mathrm{pH}$.

\section{Removal Efficiency of Total suspended solids:-}

The electric conduction increased and TSS decreases after treatment. High conductivity is due to presence of $\mathrm{Ca}^{++}$ ions. It is permissible according to WHO in waste water (guideline for drinking water) ${ }^{6}$

\section{Removal efficiency of oil \& greases:-}

Maximum amount of Oil and grease were removed in ETP. In settling tank removal percentage decreases by aeration. Maximum removal is done by diffuser and frothing of water.

Total hardness:- Total hardness of water increases after treatment in ETP as shown in table-1 (Neeri) ${ }^{7}$

\section{Removal of COD:-}

Waste water from edible oil refinery has high value of COD and BOD. In ETP, chemical treatment is done where $97.3 \%$ COD decreases (Table-1) 


\section{Removal of BOD:-}

Same as removal efficiency of BOD in waste water from edible oil refinery of ETP. Inadequate mixing of acidic waste water in alkaline waste water tank So BOD removal efficiency is medium, after lime mixing in settling tank, BOD removal efficiency decreases as shown in table-1.

\section{Removal of metal:-}

Metal like of $\mathrm{Fe}, \mathrm{Zn}, \mathrm{Mo}, \mathrm{H}_{\mathrm{g}}$ and $\mathrm{Cd}$ are also present in waste water which are removed after ETP treatment.

\section{Conclusion:-}

The studies concluded that the oil refining waste water is easily amenable to chemical \& biological treatment. The effectiveness of the treatment process was different for each parameter monitored. COD load could be importantly decreased with a decrease in oil \& grease concentration. But this water in not suitable for agriculture. So it needs further treatment. It is necessary to improve water quality coming out from effluent treatment plant using some biological methods so that it becomes suitable for public use.

\section{References:-}

1. Aslans characterization and biological treatability of edible oil waste water. Polish J of environ. Studies, 2009, Vol 18, No. 4, 533-538

2. Mkhize S.P, Alkinson, B.W and F Bux, Assessment of a Biological Nutrient Removal Process for Remediation of edible oil effluent presented at WISA 2000.

3. E Tang, 'A study of performance of waste water treatment system for small sites" world Academy of science, Engineering and Technology, $2011 \mathrm{Vol} 5$, pp. 12-29

4. Sandile p. makhize and Faizal Bux, Assessment of activated Sludge to remediate edible oil effluent, South African Journal of science, 2001, Vol-97, pp-380-382.

5. Chipasa KB limits of Physiochemical treatment of waste water in the vegetable oil refining industry. Polish Journal of Environmental Studies 2001; 10(3) 141-147.

6. Guidelines for drinking water quality $3^{\text {rd }}$ edition Vol-1 world health organisation Geneva 2004.

7. Neeri Manual on water and waste of water analysis Neeri Nagpur India. 